Tine Woergaard Knoth* \& Lise Bernhardt*

\title{
Mentale rum og kohærens
}

\begin{abstract}
This article sets out to describe the relationship between mental spaces and text coherence. When a reader interprets a text he mentally divides it into smaller parts, so-called mental spaces. The question is how texts cohere in spite of the fact that the mental spaces in principle work against text coherence because of their dividing function.

The article will show that text reference helps to establish text coherence but only the macro level makes the text fully cohere.

\section{Hvad er mentale rum?}

Når en afsender producerer en tekst, sker dette ud fra en mental model, som han har om det, teksten skal omhandle. Når en modtager derefter reciperer denne tekst, opbygger han på baggrund af afsenderens sproglige instruktioner i teksten og på baggrund af pragmatisk viden (viden om verden) en ny mental model af det reciperede. Kommunikationspartnernes mentale modeller af det, teksten omhandler, kan inddeles i underdomæner, i mentale rum ${ }^{1}$, som kan siges at være mindre "kasser", som en teksts sagsforhold, det vil sige sætningernes indhold, lægges i, alt efter hvilket forhold de har til det, der fremstår som sandt i tekstverdenen. Således er mentale rum med til at organisere og strukturere tekstens information. Dette sker så at sige "bag scenen", i kulissen, i modtagerens kognition, mens selve scenen består af de eksplicit ytrede sproglige strukturer:
\end{abstract}

1 Teorien om mentale rum er udviklet af Gilles Fauconnier, hvis bog Mental Spaces. Aspects of Meaning Construction in Natural Language (1994, 1. udgave 1985) udgør denne artikels udgangspunkt.

* Tine Woergaard Knoth Kobenhavns Universitet Elementarkursus $i$ Grask og Latin Kobmagergade 50A, 2. sal DK-1150 Kobenhavn K
* Lise Bernhardt Kфbenhavns Universitet Institut for Germansk Filologi Njalsgade 80 DK-2300 Kobenhavn $S$ 
"Mental spaces - the connections linking them, the linguistic, pragmatic, and cultural strategies for constructing them - are a significant part of what is happening backstage, behind the scenes, in the cognitive background of everyday speaking and commonsense reasoning. The principles governing the operations are, in themselves, simple and general." (Fauconnier 1994: XVII)

Resultatet er et helt netværk af mentale rum, som modtageren bevæger sig igennem på en slags "mental rumvandring", alt imens teksten udfolder sig.

Når en modtager reciperer en tekst, inddeler han den altså i mentale rum. Denne inddeling fører til, at teksten opsplittes i mindre dele, og man kunne derfor frygte, at teksten ville falde fra hinanden og blive usammenhængende, da en opsplitning af teksten i princippet modarbejder dens sammenhæng. Men da dette ikke er tilfældet, idet de fleste tekster jo opfattes som sammenhængende af modtageren, kan følgende spørgsmål stilles: Hvis mentale rum opsplitter en tekst i mindre dele, hvad er så mentale rums forhold til kohærens? Kohærens er et teksttranscendent fænomen, der vedrører tekstens indholdsmæssige sammenhænge. En tekst er kun kohærent, når der er "Sinnkontinuität", det vil sige meningssammenhæng, som stemmer overens med modtagerens pragmatiske viden (Beaugrande/Dressler 1981: 88).

Denne artikel vil se på begrebet mentale rum i lyset af kohærensbegrebet og undersøge nogle af de faktorer, der kan bidrage til kohærensskabelsen i en tekst på trods af opdelingen af teksten i mentale rum.

En tekst indeholder altid et basisrum, som er det rum, ud fra hvilket værdierne af samtlige rums sagsforhold måles. Når man skal definere en teksts basisrum, må man skelne mellem to dimensioner. Ideelt set er det ultimative basisrum tekstens interpersonelle dimension, altså kommunikationspartnernes indbyrdes forhold i kommunikationssituationen. Men af beskrivelses $\varnothing$ konomiske grunde udelades denne dimension ofte, da den er en så implicit del af tekstens funktion, at den ofte ikke behøver blive nævnt eksplicit. Praktisk set er basisrummet således oftest defineret ud fra de sagsforhold i teksten, der fremstår som sande i tekstverdenen, altså ud fra den ideationelle dimension ${ }^{2}$ (i modsætning til i logikken, hvor sagsforholdene skal være sande i forhold til den ikke-sproglige verden). Dette rum kaldes normalt speakers real-

2 Begreberne interpersonel og ideationel dimension stammer fra Halliday (1996). 
ity, reality space eller realitetsrummet. Denne artikel er baseret på analyser af avisartikler, og her er det ideationelle basisrum normalt lig med afsenderens, altså journalistens, opfattelse af virkeligheden eller fremstilling af denne, og det er således journalistens virkelighedsopfattelse, som er målestok for alle sagsforholdenes sandhedsværdier ${ }^{3}$.

Fra basisrummet kan der opsættes et eller flere nye mentale rum $\mathbf{M}_{1}$, $M_{2} \ldots M_{n}$, som dog på grund af sprogets af fysiske grunde tvungne linearitet må følge efter hinanden. Et nyt rum vil altid være inkluderet $\mathrm{i}$ og dermed afhængigt af et andet rum, som således er dettes ophavsrum (parent space), der enten kan være basisrummet eller et andet opsat rum.

Et mentalt rum kan opsættes på to måder: ved hjælp af en eksplicit lingvistisk indikator og/eller ved hjælp af pragmatisk viden. Der eksisterer dog ikke en komplet udregningsmåde, hvorpå man udelukkende ud fra den tilgængelige tekst kan definere, hvornår og hvordan et nyt rum opstår. Det er meget afhængigt af det enkelte tilfælde. Dette svarer til den almindelige opfattelse af, hvordan mentale modeller opstår, hvor inferens spiller en stor rolle, hvorfor der ikke er nogen udregningsmåde for, hvordan en modtager reciperer en tekst.

Fauconnier (1994) opstiller ikke nogen "facitliste" over de rumtyper, som han selv mener findes, men han opererer samlet set med følgende rum: speakers reality (realitetsrum, $\mathrm{R}$ ), generics (generisk rum, G), space space (lokativisk rum, L), time space (temporalt rum, T), hypothetical space (hypotetisk rum, H), counterfactuals (irrealt rum, IR), possibility space (eventuelt rum, E), image space (afbildningsrum, I), domain space (konstitutivt rum ${ }^{4}, \mathrm{~K}$ ) og believe space (anskuelsesrum, A). Dertil kan tilføjes det interpersonelle rum $\mathrm{P}$.

3 I skønlitteratur vil basisrummet være det, der i den fiktive tekstverden fremstår som sandt.

4 Fauconnier kalder selv disse rum for domæne-rum (domain spaces), men rummene kaldes her konstitutive rum, da det synes, som om Fauconnier er blevet inspireret af (den sene) Wittgensteins beskrivelse af spil, især skak, hvori det fremgår, at spil består af både konstitutive og regulative regler. Mens de regulative regler styrer valget mellem de legitime muligheder for træk med brikkerne, skaber de konstitutive regler selve spillet ved at definere formål, at legitimere træk og at give brikkerne værdi. Uden de konstitutive regler eksisterer der således intet spil (Hollis 1995: 152f). På samme måde opsætter et konstitutivt rum et helt nyt regelsæt eller helt nye love med egne værdier. 
Disse rumtyper er defineret ud fra forskellige faktorer såsom tid, lokalitet, epistemiske og evidentielle værdier. Med epistemisk værdi menes sagsforholds sandhedsværdi i forhold til tekstens ideationelle udgangspunkt, altså til det, der fremstår som sandt i tekstverdenen. Det vil sige, at sagsforhold, der er kontradiktoriske, ikke har samme epistemiske værdi og derfor ikke kan tilhøre samme mentale rum.

Med evidentiel værdi menes, at man bestemmer et sagsforholds værdi ud fra, hvem der oprindeligt har ytret det. Således spiller udsagnets ophavsmand (og dermed dets perspektiv eller point of view) og ophavsmandens mentale aktivitet også en rolle i tilskrivningen af sandhedsværdi til sagsforhold (Falster Jakobsen 1996a: 247):

\footnotetext{
"Perspective is the introduction of a subjective point of view that restricts the validity of the presented information to a particular subject (person) in the discourse. A discourse segment is perspectivized if its relevant context of interpretation is a person-bound, embedded space within the narrator's reality." (Sanders/Redeker 1996: 293)
}

\section{Mentale rum og kohærens}

Et fænomen, der er med til at skabe kohærens i en tekst, er tekstreferens. Samtidig med, at et sprogligt tegn refererer til en entitet i tekstverdenen og dermed til et koncept i kognitionen, kan det også referere til foregående sproglige tegn i teksten. Tekstreferens opstår, når et sprogligt tegn $\mathrm{i}$ en tekst refererer tilbage til et andet sprogligt tegn i teksten. Dette sker ved, at modtageren skønner, at begge tegn gennem deres indhold refererer til den samme entitet i tekstverdenen.

Spørgsmålet er, om et mentalt rum udelukkende har sin egen afgrænsede referensopbygning, eller om tekstreferensen kan bevæge sig gennem flere forskellige mentale rum og dermed være med til at binde dem sammen:

\footnotetext{
${ }^{\text {RI }}$ Wohin $^{1}$ werden die Taliban ${ }^{2}$ sich also jetzt wenden? ${ }^{\text {El }}\{$ Nach Norden gegen die verwundbare Südflanke Rußlands und die forciert anti-

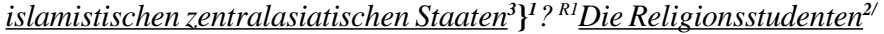
${ }^{3}$ haben schon angekündigt, ${ }^{A}\left[{ }^{R 2}\right.$ in den Blauen Moscheen von Buchara $\underline{\text { und Samarkand }}^{3}$ beten $^{3}$ zu wollen.] ${ }^{\text {E2 Oder geht es nach Osten }}{ }^{1},{ }^{R 1} \underline{\text { wo }}^{1}$ ${\underline{\text { Pakistan }^{1 / 4}}}^{\text {schon längst nicht mehr die Geister }}{ }^{3 / 5}$ kontrollieren kann, $\underline{\text { die }}^{5} \underline{\text { es }}^{4}$ einst gerufen hat? In $\underline{\text { Pakistan }}^{1 / 4}$ schreitet die "Talibanisierung"' unaufhaltsam voran. ${ }^{E 3}$ Oder geht es nach Kaschmir ${ }^{I},{ }^{R 1} \underline{\text { wo }}{ }^{I}$ die $\underline{\text { Gotteshelden }}^{2 / 3}$ bereits den Heiligen Krieg ${ }^{3}$ ausgerufen haben? Auch
} 
$\underline{\text { China }}^{6}$ wird schon nervös wegen $\left\{\right.$ seiner $^{6}$ muslimischen Provinz $^{-1}$

Xinjiang $\}^{3} . "($ Zeit 15.10.98: 10)

$\mathrm{R}=$ Realitetsrum

$\mathrm{E}=$ Eventuelt rum

$\mathrm{A}=$ Anskuelsesrum

Dette tekststykke består af seks referensrelationer. Mens referensrelation 2, 4, 5 og 6 kun optræder inden for ét mentalt rum, nemlig realitetsrummet $\mathrm{R} 1$, og dermed "kun" er med til at skabe sammenhæng inden for dette, bevæger referensrelation 1 og 3 sig gennem flere forskellige mentale rum.

Referensrelation 1 omhandler spørgsmålet om, hvor die Taliban vil bevæge sig hen. Dette spørgsmål, udtrykt gennem det interrogative pronomen wohin $^{1}$, optræder i realitetsrummet R1, og retningsmulighederne, som tilhører samme referensrelation, optræder i de tre eventuelle rum: i det eventuelle rum E1 ved hjælp af substantivsyntagmet nach Norden gegen die verwundbare Südflanke Rußlands und die forciert antiislamistischen zentralasiatischen Staaten, i det eventuelle rum E2 ved hjælp af substantivsyntagmet nach Osten, det relative pronomen wo og propriet Pakistan og i det eventuelle rum E3 ved hjælp af nach Kaschmir og wo. Således bindes de tre eventuelle rum sammen med hinanden og med realitetsrummet ved hjælp af referensrelation 1.

Referensrelation 3 indeholder en isotopi omhandlende Islam. Den opsættes i det eventuelle rum E1 gennem substantivsyntagmet die forziert anti-islamistischen zentralasiatischen Staaten ${ }^{3}$, og der refereres tilbage $\mathrm{i}$ anskuelsesrummet A gennem substantivsyntagmet den Blauen Moscheen von Buchara und Samarkland og verbet beten. Herefter refereres tilbage gennem substantivsyntagmerne die Geister, die Gotteshelden og den Heiligen Krieg i realitetsrummet R1.

${ }^{{ }_{\mathrm{R} 1}}$ Ursprünglich sieht das Gesetz vor, $\{$ daß der "Parlamentarische" einem Minister ${ }^{1 / 3}$ zugeordnet wird, und zwar im Einvernehmen mit ihm ${ }^{\mathbf{3}}$. ${ }^{\mathrm{IR}} \underline{\text { Der Minister }}{ }^{1 / 3}$ hätte also ein Mitsprache-, ja sogar ein Vetorecht bei $\underline{\text { der Auswahl }}\}^{4}$. Das ${ }^{4}$ würde voraussetzen, daß zunächst die Bundesregierung $^{1}$ gebildet wird und da $\beta$ sodann jeder Minister $^{1 / 3}$ mit $^{2}$ dem Kanzler ${ }^{1 / 5}$ darüber entscheidet, $\left[{ }^{\mathrm{A}}\left[{ }^{\mathrm{R} 2} \underline{\text { wen }}^{2} \underline{\text { er }}^{3} \underline{\text { sich }}^{3}\right.\right.$ als "Parlamentarischen"1/2 beigesellen möchte.]] ${ }^{\mathrm{R} 1}$ Aber in der Praxis gehören die "Parlamentarischen"1/2 längst zur Patronage des Kanzlers ${ }^{1 /}$ 5 (oder der Koalitionspartner ${ }^{1}$ )." (Zeit 15.10.98: 6)

$\mathrm{IR}=$ Irrealt rum 
Dette eksempel indeholder fem referensrelationer. Referensrelation 1 indeholder en isotopi omhandlende Tysklands parlament og optræder i realitetsrummet R1, i det irreale rum IR, i anskuelsesrummet A inden for det irreale rum og til slut igen i realitetsrummet $\mathrm{R} 1$.

Referensrelation 2 optræder her først i realitetsrummet R1, dernæst i anskuelsesrummet $\mathrm{A}$ inden for det irreale rum og til sidst $\mathrm{i}$ realitetsrummet R1, således at der opstår en sammenhæng mellem realitetsrummet, det irreale rum og anskuelsesrummet.

Referensrelation 3 i tekststykket opsættes i realitetsrummet R1 og optræder dernæst i det efterfølgende irreale rum IR og til slut i anskuelsesrum A inden for det irreale rum.

Referensrelation 4 optræder både i realitetsrummet R1 og det irreale rum IR, hvilket også er tilfældet med referensrelation 5 .

Et mentalt rum kan altså udover at have sin egen afgrænsede referensopbygning normalt også have referensrelationer, der rækker ud over det enkelte mentale rum og bevæger sig ind i andre mentale rum. Det er altså muligt for entiteter at optræde samtidigt i forskellige mentale rum, som har hver deres epistemiske eller evidentielle værdi. Det vil sige, at referensrelationer ubesværet kan bevæge sig ind og ud gennem alle typer mentale rum med hver deres epistemiske eller evidentielle værdi, uden at dette forstyrrer modtagerens forståelse af teksten, og således er tekstreferens et vigtigt middel til at binde mentale rum, og dermed hele teksten, sammen.

${ }^{{ }_{\mathrm{R} 1} A n}$ diesem Wochenende schiebt sich die grüne Partei ${ }^{1} \underline{\text { das }}$ $\underline{\text { Fieberthermometer }}^{2}$ unter die Zunge $\underline{e}^{1 / 2}$. Sie $\underline{1}^{1}$ will wissen, wie es $\underline{\mathrm{ihr}}^{1}$ geht, nach der wochen-, ja monatelangen Dauerleistung...

$\underline{\text { Sie }}^{1} \underline{\text { streiten nicht }}^{3}, \underline{\text { sie }}^{1}$ arbeiten diszipliniert ${ }^{3}$ und haben manchen Symphatieträger in die vorderen Reihen des Staates entsandt. Selbst $\underline{\text { Kanzler Schröder }}^{\mathbf{4}}$, \{nicht eben ein Vorkämpfer \{rot ${ }^{\mathbf{4}}$-grüner ${ }^{\mathbf{1}}$ Allianzen $\left.\mathbf{Y}^{5}\right\}^{4}$, lobt den kleinen Partner ${ }^{1}:{ }^{\mathrm{A} 1}\left[{ }^{\mathrm{R} 2}\right.$ Die Grünen $\left.{ }^{1}\right],{ }^{\mathrm{R} 1}$ erklärte $\underline{e r}^{4}$ vor feiernden Genossen, ${ }^{\mathrm{A} 1}\left[{ }^{\mathrm{R} 2}\right.$ hätten den geringsten Anteil an den Problemen $^{3}$ der Koalition $^{5}$.]

${ }^{\mathrm{R} 1}$ Warum also bangen $\underline{\text { die Grünen }}^{1}$ um $\left\{\underline{\text { ihre }}^{1}\right.$ Temperatur $^{2}{ }^{2}$. Weil sie ${ }^{1}$ dem Frieden $^{3}$ nicht trauen. Es geht zu glatt. ${ }^{\mathbf{G}}$ Wer einmal quer durch $\underline{\text { den Weltraum geschossen }}^{6}{\text { wird, } \text { will wenigstens ein Schleudertrauma }^{6}}^{6}$ erleiden. 
${ }^{\mathrm{R} 1}$ Keine neunzehn Jahre ist es her, daß $\underline{\text { sich }}^{1}$ die Grünen ${ }^{1}$ als ${ }^{\mathrm{A} 2}\left[{ }^{\mathrm{R} 3}\right.$ "Alternative zu den herkömmlichen Parteien ${ }^{4}$ "] ${ }^{\mathrm{R} 1}$ (Bundesprogramm) gegründet haben." (Zeit 10.12.98: 6)

$\mathrm{G}=$ Generisk rum

I dette eksempel er det interessant at se, at det generiske rum $\mathrm{G}$ ikke bindes sammen med tekststykkets andre mentale rum ved hjælp af referensrelationer. Det generiske rum $G$ har derimod sin egen selvstændige referensrelation 6, som ikke indgår i de andre mentale rums. Den opsættes af substantivsyntagmet quer durch den Weltraum geschossen, som der refereres tilbage til ved hjælp af substantivsyntagmet ein Schleudertrauma. I det generiske rum er der ikke nogen sproglige tegn, der er en del af de andre mentale rums referensrelationer. På denne måde sker der en slags ophold i tekstens referensrelationudvikling. Dette ses f.eks. ved referensrelation 1, der optræder både i realitetsrummet R1 og i anskuelsesrummet A1, men springer det generiske rum $\mathrm{G}$ over for så igen at optræde i realitetsrummet.

Da tekststykket alligevel er kohærent, må der være noget andet, der får det generiske rum til at hænge sammen med de andre mentale rum, og således helt overtager "ansvaret"5 for kohærens, når referensrelationerne ikke er med til at hjælpe. Dette andet skal findes på et højere, mere overordnet plan, et makroniveau.

Mens tekstreferens er et kohærensfænomen, der først og fremmest skaber sammenhæng mellem enkelte sproglige tegn gennem fælles entiteter, er teksters makroniveau et kohærensfænomen, som skaber en dybere betydningssammenhæng mellem hele sagsforhold.

En teksts makroniveau kan beskrives ud fra van Dijks teori om mikroog makrostrukturer ${ }^{6}$ (van Dijk 1980a og 1980b), ud fra hvilken tekster skal opfattes som todimensionelle. Den første dimension er det horisontale mikrostrukturniveau, som befinder sig på tekstens lineære overfladeniveau. Mikrostrukturer repræsenterer den information, der er

5 At "ansvaret" står i citationstegn, skyldes, at det er i kommunikationspartnernes kognition, tekstens sammenhæng opstår, ikke i den eksplicit ytrede tekst.

6 Van Dijks makrostrukturteori har det problem, at den er meget spekulativ. Alligevel har den den fordel, at den giver et bud på, hvad der kan udgøre en teksts makroniveau. Der er nemlig ingen tvivl om, at tekster har en overordnet betydning, og at denne betydning spiller en stor rolle i interpretationen af de enkelte sagsforhold og deres indbyrdes sammenhæng. 
udtrykt eksplicit i teksten i form af en enkelt proposition eller en sekvens af propositioner ${ }^{7}$. Disse propositioner kaldes mikropropositioner:

"Under microstructures of discourse we understand... all those structures that are processed, or described, at the local or short-range level (viz., words, phrases, clauses, sentences, and connections between sentences). In other words, microstructures are the actually and directly "expressed" structures of the discourse." (van Dijk 1980b: 29)

Den anden dimension er det vertikale makrostrukturniveau. Makrostrukturer er globale tekststrukturer, der leverer en forestilling om tekstens globale sammenhæng og dermed om selve tekstbetydningen, som dermed ligger på et højere niveau end den enkelte proposition, den enkelte mikrostruktur. Således er makrostrukturerne semantiske konstrukter i kommunikationspartnernes kognition:

"Auf der Ebene der Beschreibung, auf die wir nun übergehen, wird nicht mehr in erster Instanz auf die Konnexionen zwischen Einzelnsätzen und deren Propositionen geachtet, sondern auf Zusammenhänge, die auf dem Text als ganzem beruhen oder jedenfalls auf größeren Einheiten des Textes. Diese eher globalen Textstrukturen werden wir Makrostrukturen nennen...

...Makrostrukturen von Texten [sind] semantisch; sie liefern also eine Vorstellung des globalen Zusammenhangs und der Textbedeutung, die auf einer höheren Ebene als der der einzelnen Propositionen angesiedelt ist. Somit kann eine ganze oder Teilsequenz einer großen Anzahl von Propositionen e i n e Bedeutungseinheit auf der globaleren Ebene bilden." (van Dijk 1980a: 41f)

Uden makrostrukturer kunne modtageren kun forbinde to ved siden af hinanden stående propositioner (mikropropositioner) med hinanden, hvilket ville være meget problematisk, idet to propositioner ikke behøver være direkte forbundet med hinanden, hverken leksikalsk, syntaktisk eller semantisk, selvom de står ved siden af hinanden i overfladestrukturen. Men i en kohærent tekst vil de alligevel være forbundet, nemlig gennem makrostrukturerne, som de begge er relateret til og interpreteres gennem. Det vil sige, at opbygningen af en makrostruktur er en nødvendig betingelse for at kunne forstå en tekst på det lokale plan, mikrostrukturplanet.

Makrostrukturer består af makropropositioner, der via makroregler er afledt som en semantisk følge af en enkelt eller en sekvens af mi-

7 Der bruges her begrebet proposition for at anvende van Dijks egen terminologi. 
kropropositioner. I en tekst findes der normalt flere makrostrukturer, som befinder sig på hvert deres abstraktionsniveau på den måde, at nogle makrostrukturer er afledt direkte af mikrostrukturerne, mens andre, mere overordnede makrostrukturer på et højere abstraktionsniveau selv er afledt af makrostrukturer på et lavere abstraktionsniveau. Således kan der opstå et helt hierarki af makrostrukturer på forskellige niveauer, hvoraf den mest overordnede og globale makrostruktur for hele teksten er makrostrukturen. Makrostrukturen udgør tekstens mest overordnede information, tekstens tema (van Dijk 1980a: 42).

Ovenfor var det interessant at se, at det generiske rum ikke indeholder nogen referensrelationer, der binder det generiske rum sammen med tekststykkets $\emptyset$ vrige mentale rum. Det generiske rum har derimod udelukkende sine egne selvstændige referensrelationer, som ikke overlapper med de andre mentale rums. På denne måde "springer" tekstens referensrelationudvikling et mentalt rum over. På trods af dette ophold i tekstens referensrelationudvikling opfattes teksten alligevel som kohærent af modtageren. Dette skyldes, at modtageren har en først og fremmest intuitiv ide om tekstens overordnede betydning og dens makrostrukturer, som de enkelte sagsforhold relateres til og interpreteres gennem:

${ }^{\mathrm{R} 1}$ An diesem Wochenende schiebt sich die grüne Partei das Fieberthermometer unter die Zunge. Sie will wissen, wie es ihr geht, nach der wochen-, ja monatelangen Dauerleistung...

Sie streiten nicht, sie arbeiten diszipliniert und haben manchen Symphatieträger in die vorderen Reihen des Staates entsandt. Selbst Kanzler Schröder, nicht eben ein Vorkämpfer rot-grüner Allianzen, lobt den kleinen Partner: ${ }^{\mathrm{A} 1}\left[{ }^{\mathrm{R} 2}\right.$ Die Grünen], ${ }^{\mathrm{R} 1}$ erklärte er vor feiernden Genossen, ${ }^{\mathrm{A} 1}\left[{ }^{\mathrm{R} 2}\right.$ hätten den geringsten Anteil an den Problemen der Koalition.]

${ }^{\mathrm{R} 1}$ Warum also bangen die Grünen um ihre Temperatur? Weil sie dem Frieden nicht trauen. Es geht zu glatt. ${ }^{\mathrm{G}}$ Wer einmal quer durch den Weltraum geschossen wird, will wenigstens ein Schleudertrauma erleiden.

${ }^{\mathrm{R} 1}$ Keine neunzehn Jahre ist es her, daß sich die Grünen als ${ }^{\mathrm{A} 2}\left[{ }^{\mathrm{R} 3}\right.$ "Alternative zu den herkömmlichen Parteien"] ${ }^{\mathrm{R} 1}$ (Bundesprogramm) gegründet haben. Noch vor elf Jahren geißelten sie, in schönstem Marx-Deutsch, ${ }^{\mathrm{A}}\left[{ }^{\mathrm{R} 3}\right.$ " die herrschenden Eigentums- und Verfügungsverhältnisse über die Produktionsmittel”.] ${ }^{\mathrm{R} 1}$ Ihre Solidaritätsadressen an alle Wehr-und Zivildienstverweigerer schmückten bis 1994 die Wahlprogramme. Ihr "Nein" zur Nato-Osterweiterung 
und zum Bundeswehr-Einsatz in Bosnien datiert aus diesem Jahr. Und heute? Heute regieren sie das Land." (Zeit 10.12.98: 6)

Det generiske rum, som altså består af en enkelt mikroproposition, hænger ikke umiddelbart sammen med de omkringliggende mikropropositioner gennem referensrelationer. At modtageren alligevel opfatter teksten som kohærent, skyldes, at det generiske rums mikroproposition hænger sammen med de andre mikropropositioner på tekstens overordnede kohærensniveau, nemlig igennem tekstens makrostrukturer. Tekststykkets propositioner beskriver partiet De Grønnes udvikling fra at være et lille alternativt anti-autoritært parti til at være et respekteret regeringsparti med et stort ansvar. Af dette og af anden pragmatisk viden kan modtageren udlede, at partiet har gennemgået en meget hurtig udvikling op ad den politiske rangstige, og dermed giver indholdet af det generiske rum Wer einmal quer durch den Weltraum geschossen wird, will wenigstens ein Schleudertrauma erleiden mening i forhold til de andre mikropropositioner, og således opstår der gennem tekstens makroniveauer en sammenhæng mellem de forskellige mentale rum.

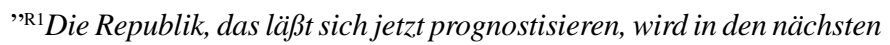
Jahren ein Novum erleben: Ein Regierungs-Duo an der Spitze, in einer komplizierten Machtbalance. Nimm's leicht, nimm zwei? Schröder, bald Kanzler, mag kalkulieren, ${ }^{\mathrm{A} 1}\left[{ }^{\mathrm{R} 2}\right.$ das sei ein Arrangement auf Zeit. Vorläufig kann an seiner Seite ein starker Zweiter nur nutzen, aber auf Dauer und im Erfolgsfalle, wenn er dann einmal sattelfest ist, werde der Kanzler schon dominieren.] ${ }^{\mathrm{R} 1}$ Mal sehen, was von der Hoffnung bleibt...

Aus dem Duo im Jahr 1998 macht Lafontaine nach Kräften eine Institution. Aber er ist gar kein Machtzyniker. ${ }^{\mathrm{H}}$ Es geht ihm, wenn man das richtig versteht, zuallererst um Stabilität. ${ }^{\mathrm{R} 1}$ Und wie! Darin übrigens sind Lafontaine und Schröder sich einig. Man tritt Lafontaine nicht zu nahe, wenn man unterstellt, ${ }^{\mathrm{A} 2}\left[{ }^{\mathrm{R} 3}\right.$ er habe niemanden gesehen, der das konzipieren kann, außer sich selbst.]

${ }^{\mathrm{G}}$ Man inszeniert nicht ungestraft! ${ }^{\mathrm{R} 1}$ Oskar Lafontaine nimmt Gerhard Schröder beim Wort. Auch das gehört zum Hintergrund des Konflikts, der an Dramatik fast schon an die Nacht von Mannheim im Jahr 1995 erinnerte, in der Scharping als nur scheinbar omnipotenter Vorsitzender von Lafontaine, Schröder und der SPD, in dieser Reihenfolge, gestürzt worden ist." (Zeit 15.10.98: 3)

$\mathrm{H}=$ Hypotetisk rum 
Heller ikke i dette eksempel hænger det generiske rums mikroproposition umiddelbart sammen med tekststykkets andre mikropropositioner ved hjælp af nogen form for referensrelation. At modtageren alligevel opfatter tekststykket som kohærent, skyldes, at der er en sammenhæng mellem propositionerne på tekstens makroniveau, nemlig gennem tekstens makrostrukturer. Gennem tekststykkets information om, at Lafontaine og Schröder har opbygget et samarbejde ud fra hver deres ambitioner og $\emptyset$ nsker, og at Lafontaine i den forbindelse vil tage Schröder på ordet, får det generiske rums proposition mening. Man inszeniert nicht ungestraft vil sige, at Schröder må stå ved sine løfter over for Lafontaine, også selvom Schröder senere skulle ændre mening. Det er således tekstens makroniveauer, der sikrer sammenhængen, mens tekstreferens kun kan betragtes som et hjælpemiddel til at sikre den overordnede kohærens, idet der også er tekstsammenhæng, selvom et mentalt rum ikke har nogen referensrelationer tilfælles med andre mentale rum i teksten.

"R1 Im Süden der koreanischen Halbinseln werden jedes Jahr 18000 Föten abgetrieben, weil sie dem "falschen" Geschlecht angehören. ${ }^{\mathrm{H}}$ Setzt man diese Zahl ins Verhältnis zur Bevölkerungszahl, spielt Südkorea die führende Rolle in einem weltweiten Krieg gegen das weibliche Geschlecht. ${ }^{\mathrm{R}}$ Seit Jahren versucht das Kinderhilfswerk der Vereinten Nationen (Unicef) mit immer drastischeren Slogans die Öffentlichkeit auf das Schicksal der missing girls aufmerksam zu machen...

${ }^{\mathrm{G}}$ Abgetriebene Mädchen bekommen keine Schlagzeilen. ${ }^{\mathrm{R} 1}$ Der für internationale Kooperation zuständige Stadtdirektor von Taegu, Sam Ryong Choi, wischt sich verstohlen Schweißperlen von der Stirn...Das Thema Mädchenvernichtung gehört eigentlich nicht in sein Ressort." (Zeit 10.12.98: 17)

Dette eksempel indeholder referensrelationer, der går igennem alle de mentale rum i tekststykket og dermed også igennem det generiske rum. Men dette er ikke den eneste sammenhæng, der findes mellem rummene. Mikropropositionerne hænger også sammen på makroniveau ved hjælp af tekststykkets makrostrukturer. Mikropropositionen i det generiske rum Abgetriebene Mädchen bekommen keine Schlagzeilen hænger sammen med tekststykkets $\emptyset$ vrige mikropropositioner via makrostrukturerne på den måde, at de beskriver, hvorledes det kvindelige køn er uønsket blandt befolkningen i Sydkorea, og at pigefostre derfor aborteres, uden at det skaber opmærksomhed. 
"R1 Und dann gibt es noch ein Foto, ${ }^{\mathrm{I}}$ auf dem die acht Herren der Pfefferküchler-Innung einträchtig beieinanderstehen. ${ }^{\mathrm{R} 1}$ Das harmonische Bild trügt. Evelin Rietschel, im Rathaus für Öffentlichkeitsarbeit zuständig, hatte uns schon am Telefon ihr Herz ausgeschüttet. ${ }^{\mathrm{A} 1}\left[{ }^{\mathrm{R} 2}\right.$ Das verstehen wir einfach nicht in der Stadt, ${ }^{[\mathrm{A} 2}\left[{ }^{\mathrm{R} 3} d a \beta\right.$ sie gegeneinander arbeiten und nicht an einem Strang ziehen.]]" ${ }^{2}$ Jeder koche sein eigenes Süppchen. "Die Konkurrenz im Westen, in Nürnberg, Aachen und Ulm, schläft nicht", ] ${ }^{\mathrm{R} 1}$ mahnt Frau Rietschel." (Zeit 10.12.98: 23)

$\mathrm{I}=$ Afbildningsrum

Også dette eksempel indeholder referensrelationer, der går igennem alle mentale rum i tekststykket, og derudover er der også en sammenhæng mellem de mentale rums sagsforhold på makroniveau, idet de hænger sammen gennem tekstens makropropositioner. Tekststykket beskriver nemlig, hvordan otte fabriksejere modarbejder hinanden i stedet for at samarbejde. I den forbindelse giver f.eks. mikropropositionen indeholdt i Jeder koche sein eigenes Süppchen mening og hænger dermed sammen med tekststykkets andre propositioner, eftersom det er en sammenfatning af forholdet mellem de otte mænd.

\section{Sammenfatning}

Selvom mentale rum i princippet splitter en tekst op i mindre dele, resulterer det ikke $\mathrm{i}$, at teksten bliver usammenhængende og falder fra hinanden. En teksts mentale rum hænger nemlig sammen på kohærensplanet. Men et kohærensskabende middel såsom tekstreferens er ikke fuldt tilstrækkeligt til at binde alle de mentale rum sammen, og det er således kun et hjælpemiddel til at få modtageren til at opfatte teksten som sammenhængende. Makroniveauet er det eneste niveau, hvor der kan skabes en fuldstændig sammenhæng mellem de forskellige mentale rum i en given tekst, og makroniveauet er således hovedårsagen til, at tekster opfattes som kohærente, også selvom der ikke optræder nogen umiddelbar sammenhæng mellem de enkelte sagsforhold og mellem de enkelte mentale rum.

Således kan modtageren undervejs i sin tekstreception foretage en "mental rumvandring" gennem teksten, idet han bevæger sig ind og ud af de forskellige mentale rum uden at tabe tråden eller miste orienteringen. 


\section{Litteraturhenvisninger}

Beaugrande, Robert-Alain de \& Dressler, Wolfgang Ulrich (1981). Einführung in die Textlinguistik. Konzepte der Sprach- und Literaturwissenschaft 28. Tübingen: Max Niemeyer Verlag.

Bernhardt, Lise \& Knoth, Tine W. (1999). Den mentale rumvandring. Et studie i mental spaces og deres forhold til kohasion og koharens. Specialeafhandling. Københavns Universitet.

Dijk, Teun A. van (1980a). Textwissenschaft. Eine interdisziplinäre Einführung. dtv. Wissenschaft. Tübingen: Max Niemeyer Verlag.

Dijk, Teun A. van (1980b). Macrostructures. An Interdisciplinary Study of Global Structures in Discourse, Interaction, and Cognition. Hillsdale New Jersey: Lawrence Erlbaum Associates Publishers.

Falster Jakobsen, Lisbeth (1996a). Mentale rum og diskursreferens. Ny forskning i grammatik 4. Odense: Odense Universitetsforlag.

Falster Jakobsen, Lisbeth (1996b). Referens, denotat, prasuppositioner, implikatur - og mentale rum. Ny forskning i grammatik, Fællespublikationen III. Odense: Odense Universitetsforlag.

Fauconnier, Gilles (1985). Mental Spaces. Aspects of Meaning Construction in Natural Language. New York: Cambridge University Press. 2. udgave 1994.

Fauconnier, Gilles (1997). Mappings in Thought and Language. Cambridge: Cambridge University Press.

Fauconnier, Gilles \& Sweetser, Eve (ed.) (1996). Spaces, Worlds, and Grammar. Chicago: The University of Chicago Press.

Fritz, Gerd (1982). Kohärenz. Grundfragen der linguistischen Kommunikationsanlyse. Tübingen: Gunter Narr Verlag.

Greimas, Algirdas Julien (1971). Strukturale Semantik. Friedr. Vieweg + Sohn. Braunschweig.

Halliday, Michael A. K. (1985). An Introduction to Functional Grammar. Arnold. London, New York, Sydney, Auckland. 4. udgave 1996.

Hollis, Martin (1994). The philosophy of social science. Cambridge: Cambridge University Press. 2. udgave 1995.

Jackendoff, Ray (1983). Semantics and cognition. Cambridge: The MIT Press.

Johnson-Laird, Philip Nicholas (1983). Mental Models. Toward a Cognitive Science of Language, Inference, and Consciousness. Cambridge: Harvard University Press.

Sanders José \& Redeker, Gisela (1996). Perspective and the Representation of Speech and Thought in Narrative Discourse. I: Fauconnier, Gilles \& Sweetser, Eve (ed.): Spaces, Worlds, and Grammar. Chicago: The University of Chicago Press.

Schwarz, Monika (1992). Einführung in die Kognitive Linguistik. Tübingen, Basel: UTB Francke. 2. udgave 1996. 
Vater, Heinz (1984). Referenz und Determination im Text. I: Sprache und Pragmatik. Stockholm: Lunder Symposium. GWK Gleerup. 